\title{
Repair of a Radial Fracture with Radial Head Luxation in a Bugio Monkey (Alouatta caraya)
}

\author{
Bruno Watanabe Minto ${ }^{1}$ Thaís Vendramini Magalhães ${ }^{1}$ Sergio Andrés Millán Guaita ${ }^{1}$ \\ Luís Gustavo Gosuen Gonçalves Dias ${ }^{1}$ Karin Werther ${ }^{2}$
}

${ }^{1}$ Department of Veterinary Clinic and Surgery, School of Agricultural and Veterinarian Sciences, São Paulo State University, Jaboticabal, São Paulo, Brazil

2 Department of Pathology, Reproduction, and One Health, School of Agricultural and Veterinarian Sciences, São Paulo State University, Jaboticabal, São Paulo, Brazil

VCOT Open 2021;4:e47-e50
Address for correspondence Bruno W. Minto, DVM, PhD, Department of Veterinary Clinic and Surgery, Faculty of Agrarian and Veterinary Sciences, São Paulo State University, Via de Acesso Prof. Paulo Donato Castellane, s/n, Jaboticabal, SP, 14884-900, Brazil (e-mail: brunowminto@gmail.com).

\begin{abstract}
Keywords

- osteosynthesis

- radius fracture

- howler monkey

- primate

Bugio monkeys (Alouatta caraya) need their arms for locomotion, hygiene, and defence, and possess well-developed dexterity of their hands, depending on them for proper feeding. For this reason, appropriate treatment of thoracic limb fractures is not only essential but also challenging in this species. This report describes the successful treatment of a radial fracture associated with luxation of the radial head in a female, adult Alouatta caraya. The patient was admitted after a suspected traumatic event with a complete transverse fracture of the right radial diaphysis and subluxation of the ipsilateral radius head. Using a craniomedial approach to the radius, surgical stabilization was performed using a $1.7 \mathrm{~mm}$ micro series Fixin locking plate after open reduction in bone fragments. The patient had early use of the limb ( 24 hours postoperatively) and progressive improvement in its usual activities over the following weeks. Radiographic monitoring was performed at 30,60, and 360 days postoperatively, and bone healing occurred with no complications. The treatment of fractures in primates is potentially challenging, requiring adaptation to primate anatomy and the specific living conditions of the species. Open reduction and stabilization of the radial fracture with a plate and manually reducing the luxated radial head effectively lead to long-term restoration of full function and of normal activities.
\end{abstract}

\section{Introduction}

Most primates have arms that are longer and more mobile than their limbs and some species also have a prehensile tail. Limbs are important, not only for locomotion but also for obtaining food. ${ }^{1}$ The howler monkey (Alouatta spp.) is considered to be a predominantly leaf-eating species but can also be frugivorous. Its feeding habits make it to spend a high proportion of time in the treetops. ${ }^{2}$ Any clinical and therapeutic approach to this species is challenging, as their

received

November 27, 2020 accepted after revision April 24, 2021
DOI https://doi.org/ $10.1055 / \mathrm{s}-0041-1731441$. ISSN 2625-2325. anatomical, physiological, and behavioural characteristics are not fully known. ${ }^{2}$ However, since there is substantial anatomical similarity of the locomotor system between monkeys and human beings, many techniques used in human orthopaedics can be applied to these monkeys in analogy. ${ }^{3}$

In general, radial fractures should be treated early because they severely impair limb function. ${ }^{4}$ In wild animals, it is essential that surgical treatment yields stable anatomical reconstruction with rapid return of limb function. ${ }^{5}$ Thoracic
(C) 2021. The Author(s).

This is an open access article published by Thieme under the terms of the Creative Commons Attribution License, permitting unrestricted use, distribution, and reproduction so long as the original work is properly cited. (https://creativecommons.org/licenses/by/4.0/) Georg Thieme Verlag KG, Rüdigerstraße 14, 70469 Stuttgart, Germany 
limbs of primates fulfil functions which differ from quadrupeds, allowing for refined arm and hand movements. This dexterity is needed to handle small food items, such as fruits and nuts, and is essential for locomotion along thin tree branches. ${ }^{2}$ The howler monkey, like a human, has opposable thumbs which are more mobile than the other fingers. ${ }^{6}$ Unimpaired hand rotation, pronation, and supination are extremely important for survival, and its restoration can be a surgical challenge. ${ }^{7}$

Plates and screws are considered superior to other implants in the treatment of most radial fractures in a human ${ }^{7}$ and in small animals. ${ }^{8}$ The successful use of locking plates in several primate species has been described, but little is known on such injuries in howler monkeys. ${ }^{3}$ We hereby report a radial osteosynthesis in a howler monkey (Alouatta caraya) using a precast locking plate.

\section{Case Report}

An adult, female howler monkey (Alouatta caraya), weighing $3.5 \mathrm{kgs}$, presented with lethargy, approximately $7 \%$ dehydration, and lameness without function of the right thoracic limb after a traumatic event. There was deviation of the axis of the right upper limb and soft tissue swelling around the right mid-antebrachium. The monkey was sedated with a combination of ketamine $(6 \mathrm{mg} / \mathrm{kg}$, Syntec, Santana de Parnaíba, SP, Brazil) and midazolam $(0.2 \mathrm{mg} / \mathrm{kg}$, Hipolabor, Sabará, MG, Brazil) intramuscularly (IM) to complete physical examination, initial emergency treatment, and laboratory and radiographic examinations. Lactated Ringer solution $(150 \mathrm{~mL})$ was administered subcutaneously, with tramadol hydrochloride $(3 \mathrm{mg} / \mathrm{kg}$ IM, Teuto, Cravinhos, SP, Brazil, IM) enrofloxacin (7.5mg / kg, Bayer, São Paulo, SP, Brazil) and meloxicam (0.2mg/kg IM, Ouro Fino, Cravinhos, SP, Brazil). Thoracic, skull, and limb radiographs were taken with a digital radiography device (digital radiography equipment; Siemens RG150/100 gl, Munich, Germany), revealing a complete transverse fracture in the mid-diaph-

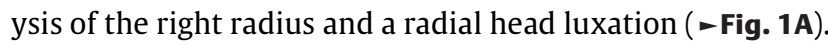
Surgical treatment was performed a day after the initial care.

Pre-anaesthetic medication consisted of ketamine (6 $\mathrm{mg} / \mathrm{kg}$ IM, Syntec, Santana de Parnaíba, SP, Brazil) and midazolam $(0.2 \mathrm{mg} / \mathrm{kg}$ IM, Hipolabor, Sabará, MG, Brazil). A left cephalic vein approach was created and the surgical field routinely prepared. The patient was pre-oxygenated by mask for 5 minutes and anaesthesia was induced with propofol $(5 \mathrm{mg} / \mathrm{mL})$. The patient was intubated with an orotracheal probe and maintained in open Baraka circuit at a flow rate of $1 \mathrm{~L} /$ minute and $100 \%$ oxygen, using isoflurane (Cristália, Itapira, SP, Brazil) as a minimum alveolar concentration of $0.8 \%$.

Additionally, a local anaesthetic block of the brachial plexus was performed with bupivacaine hydrochloride $(0.2$ $\mathrm{mg} / \mathrm{kg}$, Hypofarma, Ribeirão das Neves, MG, Brazil) guided by a neurostimulator. Monitoring (DL 1000 multiparametric monitor, Delta life) of electrocardiogram, pulse oximetry, non-invasive blood pressure, and rectal temperature was performed throughout the anaesthesia.

The animal was placed in a supine position, with the limb extended. A craniomedial approach to the radius was performed. In short, the radial extensor carpi muscles were identified and reflected cranially, and the round pronator and radial carpal flexor muscles were displaced caudally to expose the fracture site; cephalic vein, brachial vessels, and median nerve were minimally manipulated.

The luxation of the radial head was manually reduced during reduction in bone fragments and remained stable after fixation of the fracture. After reducing the bone fragments, a pre-contoured $1.7 \mathrm{~mm}$ micro series locking plate with six holes (Fixin, Rivoli, TO, Italy), five $1.7 \mathrm{~mm}$ screws, two proximal screws, and three distal screws were placed in

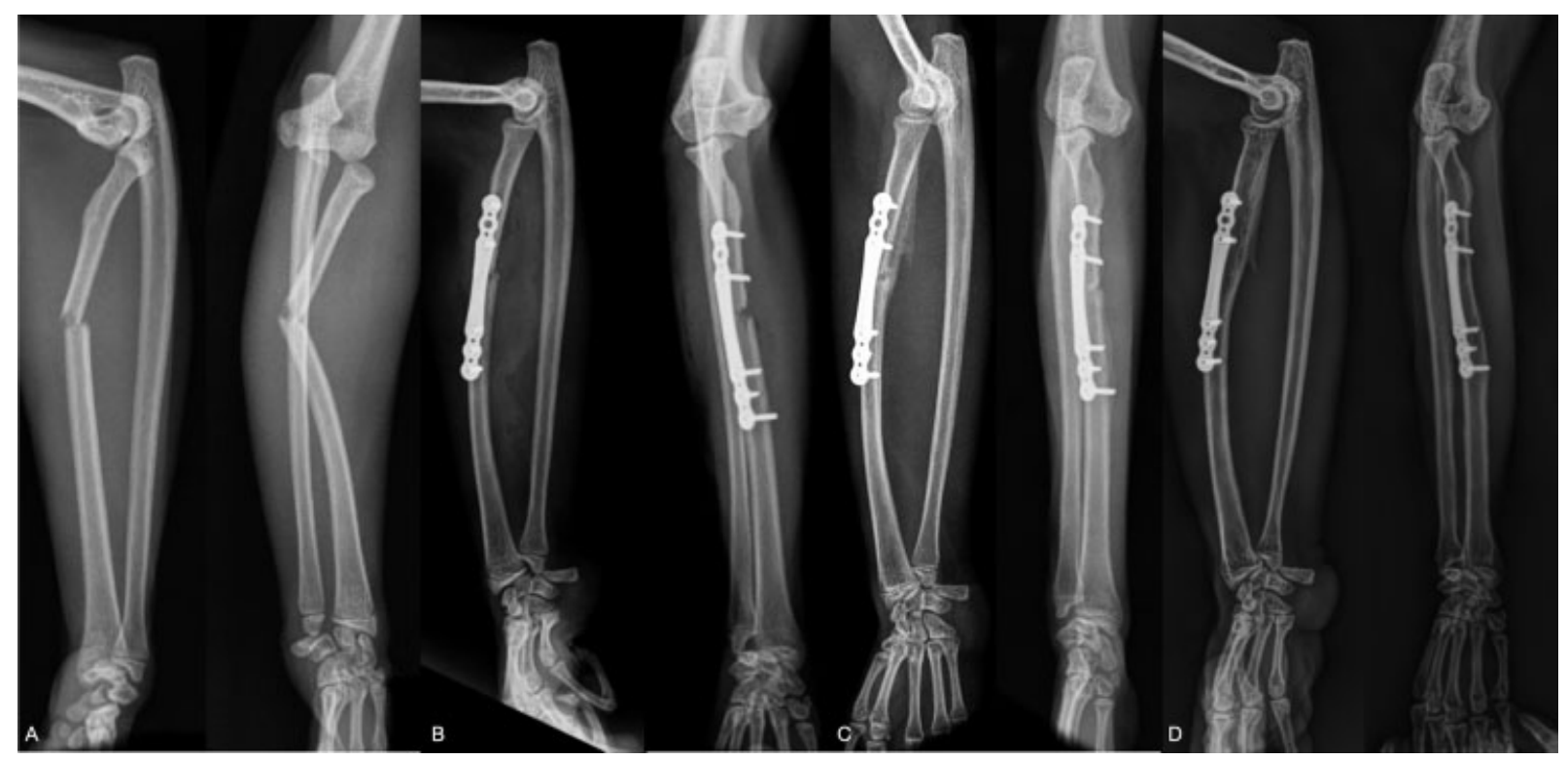

Fig. 1 Mediolateral and anteroposterior radiographic views showing a short complete oblique fracture in the middle diaphysis of the right radius and dislocation of the right radial head (A), postoperative (B), after 60 days (C), and 360 days (D). 


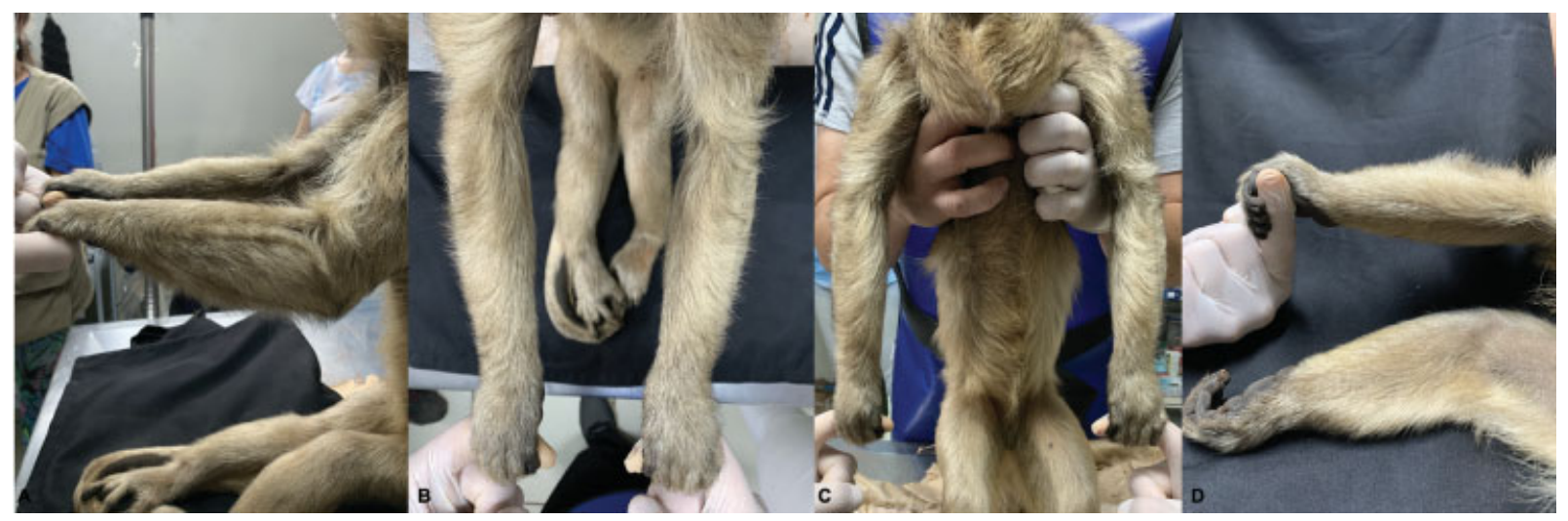

Fig. 2 Photographic images of the clinical evaluation of the right thoracic limb 1 year after osteosynthesis. Adequate extension of the limb without signs of muscular atrophy (A) and (B), symmetry of the limbs without angular deviations (C), and complete movement of the metacarpophalangeal unit, grasping and opposition of the thumb (D).

the craniomedial direction on the radial diaphysis, manually assuring interfragmentary compression. The previously retracted muscles were repositioned and were covering the implant. Closure was effectuated routinely with polyglecaprone 25 (Caprofyl 2.0, Ethicon, São Paulo, SP, Brazil) in a simple continuous pattern. The skin was sutured with nylon (Mononylon 2.0, Ethicon, São Paulo, SP, Brazil) in a separate simple pattern. Postoperative radiographs were taken (-Fig. 1B), and meloxicam (Ouro Fino, Cravinho, SP, Brazil) $0.1 \mathrm{mg} / \mathrm{kg}$, once daily, IM for 5 days, and enrofloxacin (Bayer, São Paulo, SP, Brazil) $5 \mathrm{mg} / \mathrm{kg}$, once daily, IM for 5 days, were prescribed.

The animal recovered uneventfully and was kept in a restricted space in the wildlife enclosure at the hospital for 60 days; it fed twice a day with a variety of fruits and vegetables. Functional recovery of the limb started a day after the surgical procedure, with progressive use of the limb to aid locomotion. By 7 days postoperatively, the patient exhibited unimpaired movement of the arm, hand, and digits and was handling small objects and food. Radiographic follow-up was performed at 30,60, and 360 days after surgery (-Fig. 1C and 1D), under sedation as previously described, revealed satisfactory fracture union.

After 90 days, the animal was sent to a rehabilitation programme at the local zoo. Radiographic examination was performed 360 days after the operation, at which time the animal had no noticeable impairment, full articular movements without restrictions, and no changes were identified clinically (-Fig. 2).

\section{Discussion}

Osteosynthesis of appendicular fractures of primates in the wild should aim at rapid functional recovery of the limbs and at early return of the animal to its natural habitat. To this end, a fracture must be stabilized such as to reduce the likelihood of complications and the need for after care, and to enable survival in the wild. ${ }^{5}$ We demonstrated, although only in one single case, that an upper limb fracture can be successfully treated in a bugio monkey through thorough surgical planning and by respecting species-specific anatomy and behaviour.
In our case, the patient was able to use the thoracic limb already in the immediate postoperative period for weight bearing and for feeding without apparent difficulties.

Since this primate species has very refined movements of hand and digits, including apposition of thumbs, the primary goal of fracture repair was full recovery of these complex movements which are important for feeding and locomotion on tree branches. ${ }^{9,10}$ The long digits of bugio monkeys effectively increase their range of grip, which is important for handling food and for clinbing. ${ }^{11,12}$ This great mobility and dexterity of the hands were clearly observable in the monkey reported here.

Because this wild living monkey had to be returned to its natural habitat as soon as possible, the most rigid and secure internal osteosynthesis was chosen. It had to be taken into consideration that this young female was likely to be exposed to substantial dangers when released to the wild and when disputing food resources and habitat with older and stronger competitors. $^{9}$

Fractures of the forearm can have different shapes and may be associated with joint dislocations. ${ }^{4}$ In this case, the patient presented with a dislocation of the radial head, which was returned to its anatomical position during the reduction in fragments of the radius fracture. The head of the radius in its anatomical position facilitated the fixation of the plate and the limb alignment. Open reduction and placement of an internal implant provided anatomical reconstruction and stability so that there was primary bone consolidation. To minimize the biological disadvantage of an open reduction, ${ }^{13}$ the adjacent soft tissues were handled with great care, prioritizing the preservation of all muscle and vascular structures, which provided an excellent result in the execution of all movements postoperatively.

The locking plate was the implant of choice, as it offers limited contact between the implant and the bone, minimizing vascular injury and offering great angular stability. ${ }^{14}$ Such characteristics allow a shorter time for bone healing compared with other methods of internal fixation, which is an important aspect for the treatment of wild animals. ${ }^{3}$ Tong and Guiot $^{8}$ reported radial osteosynthesis using a locking 
plate in a female old-world mandrill (Mandrillus sphinx), obtaining excellent postoperative results, as did Pizzi and colleagues $^{15}$ on a femoral fracture of a chimpanzee (Pan troglodytes verus) using double plating. The use of locking plates in human radial fracture repair has been reported with 95 to $98 \%$ success rates. $^{16,17}$ All locking screws, except the second distal screw, were placed bicortically, as it is recommended in all wild animals due to the potentially high load factors acting immediately postoperatively. 8,18

Surgical access to the radial diaphysis was obtained using a craniomedial approach, requiring no muscle incisions, which enabled rapid functional recovery of the limb. The critical structures on the medial region of the radius were carefully manipulated, especially the accessory cephalic vein in the distal portion of the diaphysis.

There are few studies referring to bone healing in monkeys $^{8-10,15}$; in our report, complete union was observed 90 days after surgery, and no clinical, anatomical, or functional impairment was seen at the long-term postoperative evaluation at 1 year, with complete preservation of all refined movements of the hand and digits.

This case report details successful treatment of a radial fracture with radial head luxation in a bugio monkey (Alouatta caraya) using a locking plate.

\section{Conclusion}

The radial fracture with radial head luxation in a bugio monkey (Alouatta caraya) was successfully repaired, with immediate return to limb function and preservation of all complex arm and hand movements, which is indicative of the success of the treatment.

\section{Funding}

FAPESP, Brazil, for the Master of Science Grant and UNESP/FCAV.

\section{Conflict of Interest}

There is no conflict of interest.

\section{Acknowledgments}

FAPESP, Brazil, for the Master of Science Grant and UNESP/FCAV, Jaboticabal, SP, Brazil.

\section{References}

1 Coimbra-Filho AF. Os primórdios da primatologia no Brasil [The beginnings of primatology in Brazil]. A Primatologia no Brasil 2004;8:11-35

2 Verona CED, Pissinatti A. Primates: primatas do novo mundo [Primates: new world primates] (Sagui, Macaco-Prego, MacacoAranha, Bugio e Muriqui). In: Cubas ZS, Silva JCR, Catão-Dias JL, eds. Tratado de animais selvagens [Treaty of Wildlife]. 2a ed. São Paulo: Rocca; 2014:723-730
3 Barranco GHF, Villela MSF, Oliveira GH, et al. Femoral osteosynthesis in Black Capuchin monkey (Sapajus nigritus) using locking plate. Acta Sci Vet 2018;46:5

4 Richard KPE, Moran CG, Apivatthakakul T, Eds. AO principles of fracture management 2 vols. Eur J Orthop Surg Traumatol 2018; 28(07):1453

5 Zimmerman DM, Dew T, Douglass M, Perez E. Femoral fracture repair using a locking plate technique in an adult captive polar bear (Ursus maritimus). Vet Surg 2010;39(02):234-238

6 Vereecke EE, Wunderlich RE. Pesquisa experimental sobre o uso e função das mãos em primatas [Experimental research on the use and function of hands in primates]. The Evolution Primate Hand 2016:259-284

7 Atesok KI, Jupiter JB, Weiss APC. Fratura de Galeazzi [Fracture of Galeazzi]. JAAOS-Journal of the American Academy of Orthopaedic Surgeons 2011;19(10):623-633

8 Tong K, Guiot LP. Minimally invasive plate osteosynthesis of fractures of the radius and ulna in a primate. Vet Comp Orthop Traumatol 2013;26(05):416-420

9 Young JW, Fernández D, Fleagle JG. Ontogeny of long bone geometry in capuchin monkeys (Cebus albifrons and Cebus apella): implications for locomotor development and life history. Biol Lett 2010;6(02):197-200

10 Lima AR, Alves JGR, Gonçalves TC, Branco É. Miologia comparada do membro torácico de Macaco-prego e Macaco-da-noite [Comparative myology of the thoracic limb of capuchin monkey and night monkey]. Acta Sci Vet 2017;45:1-8

11 Hamrick M. Evolvability, limb morphology, and primate origins. In: MJ Ravosa and Dagosto M. , eds. Primate Origins: Adaptations and Evolution. Boston, MA: Springer; 2007:381-407

12 Kirk EC, Lemelin P, Hamrick MW, Boyer DM, Bloch JI. Intrinsic hand proportions of euarchontans and other mammals: implications for the locomotor behavior of plesiadapiforms. J Hum Evol 2008;55(02):278-299

13 Van de Wall BJM, Theus C, Link BC, et al. Estabilidade absoluta ou relativa na fixação da placa para fraturas diafisárias simples do úmero [Absolute or relative stability in plate fixation for simple diaphyseal fractures of the humerus]. Lesão 2019;50(11): 1986-1991

14 Matres-Lorenzo L, Diop A, Maurel N, Boucton MC, Bernard F, Bernardé A Biomechanical comparison of locking compression plate and limited contact dynamic compression plate combined with an intramedullary rod in a canine femoral fracture-gap model. Vet Surg 2016;45(03):319-326

15 Pizzi R, Isabel Pizarro A, Mota J, De Martini C, Martinez Pereira Y, Amarasekaran B. Locking plate femur fracture repair in a juvenile Western chimpanzee (Pan troglodytes verus) in Sierra Leone. J Med Primatol 2020;49(06):352-355

16 Behnke NM, Redjal HR, Nguyen VT, Zinar DM. Internal fixation of diaphyseal fractures of the forearm: a retrospective comparison of hybrid fixation versus dual plating. J Orthop Trauma 2012;26 (11):611-616

17 Lindvall EM, Sagi HC. Selective screw placement in forearm compression plating: results of 75 consecutive fractures stabilized with 4 cortices of screw fixation on either side of the fracture. J Orthop Trauma 2006;20(03):157-162, discussion 162-163

18 Ferrigno CRA, Futema F, Fedullo DL, et al. Tratamento das fraturas do rádio, ulna e úmero com auxílio de proteína morfogenética óssea em tamanduá-bandeira (Myrmecophaga tridactyla) [Fracture treatment of the radius, ulna and humerus with the aid of morphogenetic protein bone in giant anteater (Myrmecophaga tridactyla)]. Vet Comp Orthop Traumatol 2003;16(03):196-199 